\title{
SUPREMACÍA DE LA CONSTITUCIÓN VERSUS PRIMACÍA DEL DERECHO DE LA UE EN MATERIA DERECHOS FUNDAMENTALES: CONCORDANCIAS Y DISCORDANCIAS ENTRE EL TRIBUNAL CONSTITUCIONAL Y EL TRIBUNAL DE JUSTICIA DE LA UE EN EL ASUNTO MELLONI
}

\author{
FRANCISCO JAVIER DONAIRE VILLA \\ Profesor Titular de Derecho Constitucional \\ Universidad Carlos III de Madrid
}

\begin{abstract}
SUMARIO
I. El Asunto Melloni, primer reenvío prejudicial del Tribunal Constitucional español al Tribunal de Justicia de la UE. II. El contexto europeo: La Euroorden, y su reforma en 2009 en relación con la ejecución de condenas in absentia. III. ¿Se autoexcluía el TC de la cuestión prejudicial antes del Asunto Melloni? IV. Extradición y Euroorden en caso de condena in absentia: la jurisprudencia constitucional previa al Asunto Melloni. V. Sentido del Auto 86/2011: ¿Por qué rompió el TC su «silencio prejudicial»? VI. Contenido del ATC 86/2011: dos cuestiones prejudiciales sobre la Euroorden y una sobre el artículo 53 de la Carta (más un voto particular discrepante). VII. La(s) respuesta(s) del TJUE: «primando la primacía». VIII. La recepción de la Sentencia prejudicial en la STC 26/2014: una remisión (no tan superflua) a la DTC 1/2004 y un (previsible) giro jurisprudencial respecto a las garantías constitucionales de las Euroórdenes para supuestos de condena in absentia.
\end{abstract}

\section{EL ASUNTO MELLONI, PRIMER REENVÍO PREJUDICIAL} DEL TRIBUNAL CONSTITUCIONAL ESPAÑOL AL TRIBUNAL DE JUSTICIA DE LA UE

La resolución de un recurso de amparo interpuesto por un ciudadano italiano, el sr. Melloni, contra la concesión, por la Audiencia Nacional, de una Orden Europea de Detención y Entrega (en adelante, Euroorden) destinada a 
conducirle a Italia para cumplir una condena penal de diez años a causa de una quiebra fraudulenta, propició que el Tribunal Constitucional (en adelante, TC) se decidiera en junio de 2011 a dirigirse por vez primera al Tribunal de Justicia de la Unión Europea (en adelante, TJUE), formulando tres cuestiones prejudiciales concatenadas, acerca de las garantías a observar en la concesión de Euroórdenes para ejecutar condenas pronunciadas en ausencia del entregado, y la prelación entre los sistemas nacional y de la Unión Europea (en adelante, UE) cuando sus respectivos niveles de tutela de los derechos son heterogéneos.

En uno de los aún escasos ejemplos en que un Tribunal Constitucional nacional practica esta vía de diálogo ${ }^{1}$, el ATC 86/2011 elevaba un reenvío prejudicial ante el TJUE, inaugurando así una etapa de interlocución entre ambas Cortes jurisdiccionales supremas en sus respectivos órdenes normativos. Y si bien las dos primeras cuestiones relativas a la Euroorden, que contaban con el precedente de las dos veces en que el actual TC belga se había dirigido ya al TJUE sobre la interpretación y la validez de la Decisión Marco reguladora de dicho instrumento de cooperación judicial internacional en materia penal ${ }^{2}$, la tercera cuestión prejudicial formulada por el Supremo Intérprete constitucional español, sobre el artículo 53 de la Carta de los Derechos Fundamentales, carecía de precedente en la UE, tratándose de un precepto clave por abordar la interacción de la Carta con las Constituciones de los Estados miembros, cuando el nivel de protección de los derechos que dispensa la primera sea inferior al que ofrecen las segundas ${ }^{3}$.

1 A este respecto, entre otros, véanse G. MARTinico, «Preliminary Reference and Constitutional Courts. Are You in the Mood for Dialogue?», en F. Fontanelli, P. Caroza y G. Martinico (eds.), Shaping Rule of Law through Dialogue, Europa Law Publishing, Groningen, 2010, p. 221, o A. Torres PÉreZ, «Spanish Constitutional Court, Constitutional Dialogue on the European Arrest Warrant: The Spanish Constitutional Court Knocking on Luxembourg's Door, Spanish Constitutional Court, Order of 9 June 2011, ATC 86/2011», European Constitutional Law Review vol. 8, Iss. 1, 2012, p. 105.

2 Aunque por motivos diversos de los planteados por el TC español. En Advocaten voor de Wereld VZW c. Leden van de Ministerraad, Asunto C-303/05 (STJUE de 3 de mayo de 2007), el Tribunal belga cuestionó la validez de la Decisión Marco 2002/584/JAI por disconformidad con el artículo 34.2.b) del TUE entonces vigente, regulador de esta fuente del Derecho, y por considerarse la supresión del requisito de la doble tipificación incompatible con los principios de legalidad penal y de igualdad y no discriminación, resultando en Sentencia desestimatoria. En I.B. c. Conseil des Ministres, Asunto C-306/09 (STJUE de 21 de octubre de 2010), se planteaba la interpretación de la misma Decisión Marco en torno a si una Euroorden, también para condena in absentia, puede supeditarse a que la persona afectada, nacional del Estado miembro requerido o residente en él, sea devuelta a éste para, en su caso, cumplir en él la pena que le sea impuesta a raíz de un nuevo juicio celebrado en su presencia en el Estado miembro emisor, con respuesta afirmativa del TJUE. Vid. E. CLоots, «Germs of Pluralist Judicial Adjudication: Advocaten voor de Wereld and Other References from the Belgian Constitutional Court», Common Market Law Review vol. 47, Iss. 3, 2010, pp. 645-672.

3 La novedad e importancia de esta tercera pregunta del TC español sobre el artículo 53 de la Carta de los Derechos Fundamentales de la UE es subrayada por J. I. Ugartemendía Eceizabarrena y S. Ripol CARulla, «Del recato de la jurisprudencia del Tribunal Constitucional sobre la tutela judicial de los DFUE y de las cuestiones y problemas asociados a la misma (a propósito de la STC 26/2014, de 13 de febrero), Civitas. Revista Española de Derecho Europeo, n. ${ }^{\circ}$ 50, 2014, p. 7 (citado por la versión electrónica del artículo). 


\section{EL CONTEXTO EUROPEO: LA EUROORDEN, Y SU REFORMA EN 2009 EN RELACIÓN CON LA EJECUCIÓN DE CONDENAS IN ABSENTIA}

Desde el 1 de enero de 2004, la Euroorden reemplaza a la extradición clásica en las relaciones entre los Estados miembros de la UE, de conformidad con el artículo 51 de la Decisión marco que regula aquélla (2002/584/JAI). Responde este instrumento simplificado de cooperación internacional en materia penal, según expresa la Exposición de Motivos de dicha Decisión marco, al principio de reconocimiento mutuo de resoluciones judiciales de los Estados miembros de la UE. Inicialmente definido por el Consejo Europeo como piedra angular del espacio de libertad, seguridad y justicia en las Conclusiones de Tampere en 1999, y reafirmado en el Programa de $\mathrm{La} \mathrm{Haya}{ }^{4}$, ese mismo principio ha sido explicitado en el Derecho primario por el Tratado de Lisboa ${ }^{5}$.

Una posterior modificación de la Decisión marco 2002/584/JAI, llevada a cabo por la Decisión marco 2009/299/JAI, incorporó a la primera el acervo normativo y jurisprudencial del CEDH y del TEDH en torno a que el derecho a comparecer en juicio no se configura como un derecho absoluto. En lo que a este trabajo compete, la mencionada reforma hizo desaparecer de la Decisión marco 2002/584 el concepto de rebeldía, reemplazándolo por el más genérico de condena en ausencia, dejándose de condicionar la entrega a la garantía de celebración de un nuevo proceso en el Estado emisor, al tipificarse entre los supuestos en que no procede denegar la Euroorden la incomparecencia personal del acusado, con conocimiento del juicio por parte de éste y designación de Abogado que le defienda, de oficio o de confianza.

\section{III. ¿SE AUTOEXCLUÍA EL TC DE LA CUESTIÓN PREJUDICIAL ANTES DEL ASUNTO MELLONI?}

Décadas antes del Asunto Melloni, y pocos años después de la incorporación de España a las entonces Comunidades Europeas, la STC 28/1991 «oficialmente» invitaba a los órganos judiciales ordinarios españoles al diálogo directo e inmediato con el TJUE, a través de la cuestión prejudicial, en caso de conflicto

4 Véase, a este respecto, S. Alegre y M. Leaf, «Mutual Recognition in European Judicial Cooperation: A Step Too Far Too Soon? Case Study-The European Arrest Warrant», European Law Journal, vol. 10 No. 2, 2004, pp. 200-217; V. Mitsilegas «The Constitutional Implications of Mutual Recognition in Criminal Matters in the EU», Common Market Law Review, 44, 2007, pp. 1279-1311., o S. Peers, "Mutual Recognition and Criminal Law in the European Union: Has the Council got it wrong?», Common Market Law Review, 41, 2004, pp. 5-36.

5 Acerca de la «constitucionalización» de este principio en el Derecho originario a resultas del Tratado de Lisboa, C. Ladenburger, «Police and Criminal Law in the Treaty of Lisbon. A New Dimension for the Community Method», European Constitutional Law Review, 4 (1), 2008, pp. 35-36. 
entre Derecho comunitario y ley interna. Al mismo tiempo, parecía autoexcluirse el propio TC de ese diálogo, si bien la excepción no era general, sino referida en la propia Sentencia 28/1991 a los casos de incompatibilidad de la Ley con el Derecho comunitario, lo que dejaba imprejuzgada la situación en que la incompatibilidad con el Derecho comunitario, por parte interna, lo es de la propia Constitución.

De hecho, el tema no llegaría a plantearse como opción teórica hasta la DTC 1/2004, y como realidad práctica, justamente, hasta el Asunto Melloni, con el ATC 86/2011. Y aunque se afirmaba en la Declaración 1/2004 que los problemas de hipotéticos excesos del Derecho europeo respecto de la Constitución se consideraban a la sazón inexistentes, se añadía en ella que si en la ulterior dinámica del Derecho de la UE llegase éste a ser inconciliable con la Constitución, sin que tales excesos fuesen remediados por los procedimientos en él establecidos, el TC podría abordar los problemas que en tal caso se suscitaran, en expresión de la conservación de la soberanía del pueblo español y de la supremacía de la Constitución, a través de los procedimientos constitucionales pertinentes.

Cabe discernir en estas afirmaciones del TC español una «autollamada», no precisamente implícita, al diálogo judicial directo e inmediato con el TJUE, a diferencia de lo señalado en la STC 28/1991 respecto al control de la adecuación de la ley interna al Derecho comunitario. Más explícita aún quedaba esa «autollamada», en términos casi proféticos dada la perspectiva que posteriormente ha ofrecido el Asunto Melloni, cuando la misma DTC 1/2004 se detenía en el problema específico de la dualidad de círculos de protección de los derechos fundamentales, nacional y comunitario, y en las dificultades de articulación cuando los respectivos niveles de tutela sean distintos (y más concretamente, cuando el nivel comunitario sea inferior al nacional). Sintéticamente, el diálogo a que apelaba la DTC 1/2004 habría de canalizarse mediante cuestión prejudicial surgida de recursos de amparo constitucional, pues esta es la vía de tutela para la protección de cada concreto derecho constitucional ${ }^{6}$. Justo esto fue lo sucedido con el triple reenvío prejudicial que efectuó el ATC 86/2011.

\section{EXTRADICIÓN Y EUROORDEN EN CASOS DE CONDENA IN ABSENTIA: LA JURISPRUDENCIA CONSTITUCIONAL PREVIA AL ASUNTO MELLONI}

También antes del Asunto Melloni, había generado el TC español un corpus jurisprudencial en relación con los procedimientos clásicos de extradición, que

6 Sin perjuicio de ello, tampoco puede descartarse el planteamiento de cuestiones prejudiciales por el TC al TJUE a partir de recursos o cuestiones de inconstitucionalidad sobre normas legislativas que apliquen Derecho de la UE y tengan incidencia sobre el desarrollo o régimen de ejercicio de los derechos constitucionalmente reconocidos. 
luego declaró aplicable a la Euroorden. Dentro de este acervo, la STC 91/2000, codificando y desarrollando jurisprudencia anterior, abordó en extenso la cuestión de la condicionalidad por respeto a las garantías dimanantes del derecho fundamental a la tutela judicial efectiva, y en concreto, dentro de él, del derecho de defensa ${ }^{7}$. Una vez aprobada y en vigor su Decisión marco reguladora (2002/584/JAI), y tras la ulterior adopción de la Ley interna española que la incorpora a nuestro ordenamiento, la Ley 3/2003, mimetizó el TC a la Euroorden con la extradición en cuanto al respeto de los derechos fundamentales a un proceso con todas las garantías y de defensa, por lo que respecta a la concesión o denegación de este instrumento de cooperación judicial en materia penal para ejecución de condenas dictadas por otro Estado miembro en ausencia de la persona entregada.

En la STC 83/2006, se declaró aplicable a la Euroorden el principio de legalidad extradicional ex artículo 13.3 de la Constitución, cuya observancia quedaba encuadraba en el derecho a la tutela judicial efectiva (artículo 24 de la Norma Fundamental), y no en el principio de legalidad sancionadora (artículo 25 de la Ley de leyes). Posteriormente, y evocando que la STC 91/2000 había considerado una vulneración indirecta de los derechos a un proceso con todas las garantías y de defensa la falta de condicionamiento de la extradición para ejecución de condenas in absentia a nuevo juicio presencial en el Estado requirente, la STC 177/2006 de forma expresa asimiló la Euroorden a la extradición en esos mismos supuestos $^{8}$. Por último, la STC 199/2009, invocando las SSTC 91/2000 y 177/2006, reiteró el obligado condicionamiento a juicio rescisorio presencial, con la novedad de que fue pronunciada ya tras la reforma, a la sazón recién aprobada en 2009, de la Decisión marco de la UE sobre la Euroorden (2002/584/JAI) justamente en relación con las condenas dictadas en ausencia voluntaria del acusado ${ }^{9}$, si bien con sendos Votos Particulares, suscritos por los Magistrados

7 Para mayores detalles respecto a esta resolución, véanse M. Pulido QueCEdo, «El Tribunal Constitucional como Tribunal Penal Internacional (Nota crítica de la STC 91/2000)», Repertorio Aranzadi del Tribunal Constitucional, n. ${ }^{\circ} 1$ 2000, pp. 1760-1762, F. REY MARTínez, «El problema constitucional de la extradición de condenados en contumacia. Comentario de la STC 91/2000 y concordantes», Teoría y Realidad Constitucional, n. 5, 2000, pp. 289-335, I. Torres Muro, «Enseñar al que ya sabe. Las extradiciones ante el Tribunal Constitucional (STC 91/2000)», Repertorio Aranzadi del Tribunal Constitucional, n. ${ }^{\circ} 2$ 2000, pp. 18591884, o J. I. Ugartemendía Eceizabarrena y S. Ripol Carulla, «Del recato de la jurisprudencia del Tribunal Constitucional...», cit., apdo. I.1.

8 Mayores detalles sobre las implicaciones de esta resolución pueden hallarse en el trabajo de T. DE LA QuAdRA-SALCEDO JANINI, «El encaje constitucional del nuevo sistema europeo de detención y entrega. Reflexiones tras la STC 177/2006, de 5 de junio», Revista Española de Derecho Constitucional, n. ${ }^{\circ}$ 76, 2006, pp. 277-303. Véase, asimismo, F. Izurzun Montoro y C. Mapelli Marchena, «Orden Europea de Detención y Constitución. (Comentario a la Sentencia del Tribunal Constitucional 177/2006, de 5 de junio», Noticias de la Unión Europea, n. ${ }^{\circ} 282,2008$, pp. 15-29.

9 Acerca de esta Sentencia, cfr. los comentarios de M. CEDEÑo HeRnÁN, «Vulneración indirecta de derechos fundamentales y juicio en ausencia en el ámbito de la orden europea de detención y entrega. A propósito de la Sentencia del Tribunal Constitucional 199/2009, de 28 de septiembre», Revista General de Derecho Europeo, n. ${ }^{\circ}$ 20, 2010, pp. 1-15, D. Rodríguez Horcajo, «Derecho Europeo y Derecho nacional: dos piezas 
Rodríguez Zapata y Pérez Tremps, rechazando tal asimilación de la Euroorden al régimen de garantías de la extradición clásica.

Debe significarse, además, que la jurisprudencia constitucional relativa a la Euroorden se había ceñido, antes de Melloni, a las garantías concretas en supuestos de condenas in absentia, sin haber existido en España impugnación de la Ley de incorporación de la Decisión Marco reguladora de la Euroorden (2002/584/ JAI), como sí había sucedido en otros Estados miembros, cuyos Tribunales Constitucionales se han pronunciado sobre la constitucionalidad interna de las respectivas leyes de ejecución de la Euroorden, aunque por motivos distintos: en todos los casos, la constitucionalidad de la entrega de los propios nacionales ${ }^{10}$.

\section{SENTIDO DEL AUTO 86/2011: ¿POR QUÉ ROMPIÓ EL TC SU «SILENCIO PREJUDICIAL»?}

Poca luz arrojaba el ATC 86/2011, en sus antecedentes, sobre el porqué del reenvío prejudicial al TJUE, pues no reflejaban éstos ni los motivos esgrimidos por el Pleno para avocar el recurso de amparo del que surgen las tres cuestiones planteadas, ni las alegaciones de las partes al respecto, salvo la sucinta mención a la oposición del Ministerio Fiscal por estimar que la Decisión Marco 2002/584/ JAI reguladora de la Euroorden no resultaba aplicable ratione temporis al litigio, lo que a juicio de este último tornaba innecesaria la decisión prejudicial del TJUE para resolver el amparo solicitado.

Uno de los posibles desencadenantes tal vez fuera la vigorosa crítica académica a la doctrina de la violación indirecta del artículo 24.2 de la Constitución por la no condicionalidad a juicio rescisorio en el Estado requirente de las Euroórdenes para ejecución de condenas in absentia ${ }^{11}$. Cabe también pensar en los Votos

(a veces) difíciles de encajar. Comentario a la Sentencia del Tribunal Constitucional 199/2009, de 28 de septiembre», Revista General de Derecho Penal, n. ${ }^{\circ} 14,2010$, pp. 1-17, o A. Torres Pérez, «Euroorden y conflictos constitucionales: a propósito de la STC 199/2009, de 28.9.2009», Civitas. Revista Española de Derecho Europeo, n. ${ }^{\circ}$ 35, 2010, pp. 441-471.

10 S. Iglesias SÁNCHEZ, «La jurisprudencia constitucional comparada sobre la Orden Europea de Detención y Entrega, y la naturaleza jurídica de los actos del tercer pilar», Revista de Derecho Comunitario Europeo, enero/abril 2010, p. 171. Para mayores detalles, entre otros, véanse J. KoMÁREK, «European Constitutionalism and the European Arrest Warrant: In Search of the Limits of «Contrapunctual Principles», Common Market Law Review, n. ${ }^{\circ}$ 44, 2007, pp. 9-40; L. I. Gordillo PÉREZ, «El juez nacional y el juez europeo ante la Euroorden», en M. Revenga SánChez (coord), El Poder Judicial. VI Congreso de la Asociación de Constitucionalistas de España, Tirant lo Blanch, Valencia, 2009, pp. 755-790; E. GuILD (ed.), Constitutional Challenges to the European Arrest Warrant, Wolf Legal Publishers, Nijmegen, 2006, O. Pollicino, «European Arrest Warrant and Constitutional Principles of the Member States: a Case Law-Based Outline in the Attempt to Strike the Right Balance between Interacting Legal Systems», German Law Journal, vol. 09, No. 10, 2008, pp 1313-1355.

11 Cumple remitir, en este sentido, al trabajo de I. Torres Muro, «La condena en ausencia: unas preguntas osadas (ATC 86/2001, de 9 de junio) y una respuesta contundente (Sentencia del Tribunal de Justicia de la Unión Europea de 26 de febrero de 2013)», Revista Española de Derecho Constitucional, 97, 2013, p. 349, 
Particulares a las SSTC 177/2006 y 199/2009, cuando enfatizaban que exigir esa condicionalidad podía equivaler a un incumplimiento del Derecho de la UE por España como Estado miembro, o que no casaba con la jurisprudencia del TEDH.

Y de nuevo en el ámbito académico, se han apuntado razones de política judicial: que la reiteración en la STC 199/2009 del requisito de la condicionalidad obligaba a la Audiencia Nacional a escoger en casos subsiguientes entre cumplir con la Constitución (esto es, con la jurisprudencia interpretativa de ella formulada por el TC) o con el Derecho de la Unión, generándose un riesgo doble: que la Audiencia Nacional desatendiera el mandato constitucional y diera preferencia aplicativa a la regulación de la Unión, o bien, que la propia Audiencia, ante la antinomia, planteara directamente la cuestión prejudicial, orillando al $\mathrm{TC}^{12}$.

\section{CONTENIDO DEL ATC 86/2011: DOS CUESTIONES PREJUDICIALES SOBRE LA EUROORDEN Y UNA SOBRE EL ARTÍCULO 53 DE LA CARTA (MÁS UN VOTO PARTICULAR DISCREPANTE)}

Doctrinalmente se ha hecho notar con acierto ${ }^{13}$ que hay en el Auto 86/2011, al plantear y motivar las tres cuestiones prejudiciales, una defensa ante el TJUE, por parte del TC, de su propia doctrina de la vulneración indirecta del derecho a un proceso con todas las garantías si no se condiciona la concesión de Euroórdenes para ejecución de condenas en ausencia a la disponibilidad de un juicio rescisorio con comparecencia del afectado en el Estado miembro emisor. Con este telón de fondo, se comprende mejor el esquema argumental del ATC 86/2011, y la prelación entre las tres cuestiones formuladas (de estricta subsidiariedad de cada una respecto de la antecedente, y en grado creciente de intensidad en cuanto al cuestionamiento planteado en cada una de ellas).

Buscaba primero el TC una interpretación de la Decisión Marco 2002/584/ JAI, reguladora de la Euroorden, compatible con la condicionalidad requerida en las SSTC 177/2006 y 109/2009 para su concesión en supuestos de condena in absentia. Únicamente para el caso en que no fuese posible tal interpretación conciliadora, elevaba el ATC 86/2011 una segunda cuestión prejudicial al TJUE sobre la misma Decisión Marco, pero ahora ya de validez, preguntando si su

notas 11 a 16, donde se realiza un repaso doctrinal con cita de los respectivos comentaristas críticos con la jurisprudencia del TC (Gutiérez Berlinches, Cedeño Hernán, Revenga Sánchez, De la QuaDRA-SAlCEdo Janini y Rey Martínez).

12 Así lo argumenta A. Torres Pérez, «Spanish Constitutional Court: Constitutional Dialogue on the European Arrest Warrant...», cit, p. 123.

13 A. Torres PÉrez, «Spanish Constitutional Court, Constitutional Dialogue on the European Arrest Warrant..., cit., p. 123. 
contenido vulneraba los derechos de tutela judicial efectiva y de defensa que el Derecho originario de la Unión autónomamente reconoce en la Carta de los Derechos Fundamentales, haciendo equivaler la protección que ésta dispensa al nivel de tutela otorgado por el artículo 24 de la Constitución española, según el entendimiento dado al mismo en la antecedente jurisprudencia del TC.

Sólo para una respuesta adversa (negativa) del TJUE a esta segunda cuestión, planteaba el ATC 86/2011 una cuestión de interpretación del artículo 53 de la Carta de los Derechos Fundamentales de la UE, que le permitiera oponer a la ejecución de la Decisión Marco 2002/584/JAI el (en tal hipótesis, superior) nivel de protección de los derechos un proceso con todas las garantías y de defensa que, según su jurisprudencia previa al triple reenvío, se deriva del artículo 24.2 de la Constitución española (la tan repetida exigencia de condicionalidad a juicio rescisorio en la concesión de Euroórdenes para ejecución de condenas penales graves in absentia). Proponía el ATC 86/2011 otorgar al artículo 53 de la Carta la condición de cláusula de estándar mínimo de protección, al estilo de la contenida en el artículo 53 del CEDH, lo que no impediría aplicar un superior nivel nacional de reconocimiento y garantía de los derechos (una vez más, la referida condicionalidad en la concesión de Euroórdenes para ejecución de condenas in absentia), pero sin necesidad de generalizar tal superior nivel tuitivo nacional mediante su asunción por el TJUE. Ciertamente, se erigiría con ello al artículo 53 de la Carta en excepción o límite de Derecho originario a la jurisprudencia del TJUE sobre la primacía del Derecho comunitario, manteniendo, en cambio, sin limitación comunitaria la antecedente jurisprudencia del TC. Quizás en previsión de esta constatación, argumentaba el ATC 86/2011, en razonamiento cuando menos atendible, que lo contrario significaría considerar al artículo 53 de la Carta norma delimitadora de los respectivos ámbitos de aplicación de esta última y de las Constituciones nacionales, lo que vaciaría de contenido al precepto por redundancia con respecto a lo prescrito en el artículo 51, también de la Carta, donde se dice que las Constituciones nacionales rigen fuera del ámbito en el que lo haga la propia Carta.

Como alternativa, sugería el ATC 86/2011 un compromiso, proponiendo que el artículo 53 de la Carta tuviera el valor de cláusula de estándar mínimo compatible con un superior nivel nacional de protección de los derechos, o bien el carácter de mera regla de delimitación de los ámbitos respectivos de aplicación de la Carta y de las Constituciones estatales, en función de las circunstancias concurrentes en cada caso concreto. Aunque el criterio general parezca a priori poco sólido, o al menos, dotado de escasa certeza sobre cuándo sería aplicable una solución u otra, aducía el ATC 86/2011 ejemplos respectivos para cada entendimiento: dependiendo de que la colisión sea entre derechos fundamentales, o entre un derecho fundamental o algún otro principio general del Derecho de la UE reconocido fuera de la Carta, o de que alguno de los elementos normativos en conflicto, europeo y nacional, tenga alguna estructura determinada, deslizando aquí una alusión a la Sentencia Pupino del TJUE de la cual cabría inferir que la 
prioridad sería de la Constitución nacional cuando la norma europea antinómica fuese una Decisión marco, como en el propio Asunto Melloni, o más ampliamente, Derecho adoptado en el ámbito del antiguo tercer pilar intergubernamental de la Unión, lo que, dicho sea de paso, hubiera permitido al TJUE mantener inalterada su jurisprudencia clásica sobre la primacía del Derecho comunitario.

Pese a la inteligencia que traslucen, tampoco pueden dejar de apreciarse ciertas dosis de nävveté tras estos planteamientos. En esencia, las tres cuestiones prejudiciales no hacían otra cosa que postular excepciones a la primacía de la Decisión Marco 2002/584/JAI, principio que, en general, junto al de efecto directo, son de los más «queridos» del TJUE, porque éste los ha forjado mediante su labor pretoriana, siendo además en la actualidad dos de los rasgos más vigorosamente característicos del Derecho comunitario. Se antojaba por ello más que probable la respuesta negativa a todas estas cuestiones prejudiciales, $\mathrm{y}$ al argumentario sugerido por el TC para sustentarlas, como igualmente lo era que el TJUE, del mismo modo que pretendía el TC, también deseara preservar su jurisprudencia más conocida, la relativa a la primacía del Derecho comunitario. Y aun reforzarla y ampliarla, cabe añadir (y más adelante se desarrollará), al Derecho del tercer pilar no comunitario de la Unión, pues ésa era, y sigue siendo, la naturaleza de la Decisión Marco reguladora de la Euroorden, todo ello aprovechando la ocasión que le brindaba el Alto Intérprete español.

Contó el ATC 86/2011 con un Voto Particular discrepante del Magistrado Pérez Tremps, en la línea que el mismo Magistrado sostuviera en el que formuló a la STC 199/2009. Aun saludando que el TC inaugurase una línea de diálogo judicial con el TJUE, en el Voto se consideraba en este caso innecesario el triple reenvío prejudicial. Partiendo de la cultura de derechos fundamentales compartida por los Estados miembros de la Unión Europea, con el consiguiente parámetro común de reconocimiento y protección de esos derechos (expresado en el artículo 6.2 del TUE, e integrado por elementos heterogéneos: las previsiones normativas del Derecho comunitario, la jurisprudencia del TJUE, las tradiciones constitucionales comunes de los Estados miembros, y el sometimiento de todos ellos, también, al CEDH y con él a la jurisprudencia del TEDH), dicha cultura común no permitiría a un Estado miembro, según el Magistrado, imponer a los demás su parámetro nacional de tutela de dichos derechos. De este modo, se añadía, una hipotética lesión de derechos cometida y no reparada en cualquiera de los Estados no debería repararse en otro, sino agotando las instancias internas en el primero y acudiendo al TEDH, sin que constase que en el Asunto Melloni se hubiera empleado dicho remedio jurisdiccional por el recurrente en amparo. Sólo el ordenamiento supranacional, proseguía el Voto, puede establecer excepciones a la aceptación incondicionada por un Estado miembro de las actuaciones judiciales de otro Estado miembro, siendo así que la Decisión Marco reguladora de la Euroorden, en opinión del Magistrado, no excluye cualquier condena en la que el acusado se encuentre ausente. Tampoco de la jurisprudencia del TEDH, añadía 
el Voto, se desprendería que cualquier condena en ausencia sea per se contraria al artículo 6 del CEDH, citándose a este respecto la STEDH Medenica c. Suiza de 14 de junio de 2001, apdo. 59, para finalmente concluir que los criterios que la doctrina del TC determinaba como integrantes del parámetro de enjuiciamiento interno que, en su día, hubiera de realizar el Alto Tribunal, hacían innecesario suscitar cuestión prejudicial alguna para la resolución del amparo del que partía el triple reenvío.

\section{LA(S) RESPUESTA(S) DEL TJUE «PRIMANDO LA PRIMACÍA»}

Un año y medio largo después del ATC 86/2011, de 9 de junio, recayó la respuesta del TJUE, mediante Sentencia de su Gran Sala, de 26 de febrero de $2013^{14}$, siendo ésta la resolución central del diálogo emprendido por el TC con el Tribunal supranacional europeo. El hecho de que en el procedimiento prejudicial ante el TJUE comparecieran las representaciones de nueve Estados miembros de la Unión (además de España por evidentes razones, también las de Alemania, Austria, Bélgica, Italia, Países Bajos, Portugal, Polonia y Reino Unido) da una idea de la trascendencia de las tres cuestiones planteadas por el TC español, todas ellas abordando el complejo y trascendental asunto de la relación y prelación entre Derecho de la Unión y Derecho (constitucional) interno en el relevante (y sensible) ámbito de los derechos fundamentales, y sus eventuales niveles dispares de protección nacional y comunitaria.

Si el ATC 86/2011 incorporaba en su triple reenvío prejudicial una propuesta en cierto modo transaccional dirigida al TJUE a fin de conciliar el principio de primacía del Derecho comunitario con la preservación del superior nivel constitucional nacional de protección de los derechos (esto es, con el fin de conjugar primacía del Derecho comunitario y supremacía del Derecho constitucional nacional de los derechos fundamentales), junto con el más específico (e inconfesado) propósito de mantener su jurisprudencia previa sobre Euroórdenes en casos de condenas in absentia, tanto uno como otro objetivo cosecharon un rotundo fracaso. Salvo que el planteamiento del TC fuese el «rectificar preguntando» a que entre nosotros se ha referido Revenga Sánchez ${ }^{15}$, dada la respuesta adversa que, como se verá en seguida, dispensa la Sentencia Melloni del TJUE a las tres cuestiones planteadas por el TC.

$\mathrm{Y}$ es que la contestación del Tribunal supranacional, en síntesis, rechaza el compromiso ofrecido por el TC, y opta decididamente por la primacía del Derecho de la Unión, incluso del Derecho derivado no comunitario (pues tal es el status

14 Sentencia del Tribunal de Justicia (Gran Sala), de 26 de febrero de 2013, Asunto C-399-11, Stefano Melloni.

15 M. Revenga SÁnCHEZ, «Rectificar preguntando. El Tribunal Constitucional acude al Tribunal de Justicia...», cit. 
jurídico de las Decisiones Marco, como ya se ha puesto de relieve, en su condición originaria y actual de Derecho del antiguo tercer pilar intergubernamental de la Unión). Descarta así el TJUE una lectura parcial o moderadamente «renacionalizadora» como la propuesta por el TC (o, lo que es igual, desactiva el TJUE la teoría de los contralímites constitucionales materiales implícitos en el artículo 93 de la Constitución española a la integración, a que se refiriese la DTC 1/2004 como concreta expresión de la supremacía constitucional), que aparentemente venía apoyada incluso por la literalidad del artículo 53 de la Carta de los Derechos Fundamentales de la Unión. Antes al contrario, la Sentencia Melloni del TJUE efectúa una exégesis de dicho precepto, si no en clave federalista (o «federalizante» en la gráfica terminología sugerida por Juan Ignacio Ugartemendía Eceizabarrena ${ }^{16}$ ), sí al menos, y en todo caso, de índole supranacionalista o integradora, precisamente al optar por la primacía de las disposiciones de la Unión frente a las normas constitucionales de los Estados miembros que ofrezcan un superior nivel de protección de los derechos.

Declarada la aplicabilidad al litigio principal, ratione temporis, de la modificación de la Euroorden aprobada por la Decisión Marco 2009/299, en cuanto prohíbe la condicionalidad en la concesión de Euroórdenes para ejecución de condenas penales in absentia, la respuesta en la Sentencia Melloni del TJUE, en síntesis, reposa sobre los siguientes argumentos. En primer término, sostiene el TJUE que los cuatro supuestos previstos en el apartado 1 del artículo 4 bis de la Decisión marco 2002/584 son excepciones al carácter facultativo de la denegación prevista en el precepto, y se oponen a que la autoridad judicial de ejecución subordine la entrega de la persona condenada en rebeldía a la posibilidad de que se revise la sentencia condenatoria con presencia de esa persona. Junto a la exégesis literal de los mismos, la Sentencia invoca la estructura y finalidad de la Decisión marco 2009/299, que sustituyó el antiguo artículo 5.1 de la Decisión marco 2002/584, el cual precisamente permitía tal condición, por el vigente artículo 4 bis, regulador de las situaciones en que no deberá denegarse el reconocimiento ni la ejecución de resoluciones dictadas a raíz de juicios celebrados sin comparecencia del imputado.

Tal interpretación, a decir del Tribunal supranacional, es congruente con los objetivos perseguidos por la Decisión marco 2009/299, de reforma de la regulación inicial de la Euroorden, consistentes en facilitar la cooperación judicial en materia penal, mejorando el reconocimiento mutuo de resoluciones judiciales por medio de una armonización de los motivos de no reconocimiento de las resoluciones dictadas a raíz de juicios celebrados en ausencia del imputado, sin menoscabo del derecho de defensa de éste. Y todo ello, en la medida en que

16 J. I. Ugartemendía Eceizabarrena, «La eficacia «federalizante» de los Derechos Fundamentales de la Unión Europea. Análisis de sus manifestaciones en el Derecho penal», Civitas. Revista Española de Derecho Europeo, n. ${ }^{\circ} 31,2008$, pp. 249-277. 
significa establecer un nuevo sistema simplificado y más eficaz de entrega de personas condenadas o sospechosas de haber infringido la ley, a su vez, sería conforme con el objetivo general de la Unión de realizar un espacio de libertad, seguridad y justicia.

En cuanto a la segunda cuestión prejudicial, sostiene la Sentencia Melloni del TJUE que el mencionado artículo 4 bis, apartado 1, de la Decisión marco 2002/584, redactado por la Decisión marco 2002/299, no vulnera los artículos 47 y 48 de la Carta de los Derechos Fundamentales de la Unión Europea, al considerar que, aunque el derecho del acusado a comparecer en el juicio es un elemento esencial del derecho a un proceso equitativo, no es, sin embargo, un derecho absoluto, sino que el acusado puede renunciar a él por libre voluntad, expresa o tácita, siempre que la renuncia conste de forma inequívoca, se acompañe de garantías mínimas correspondientes a su gravedad, y no se oponga a ningún interés público relevante. Y más en concreto, arguye el TJUE que no hay vulneración del derecho a un proceso equitativo si el interesado, aun cuando no haya comparecido en juicio, ha sido informado de la fecha y lugar del juicio, o ha sido defendido por un letrado al que haya mandatado al efecto, como había sucedido en el litigio principal.

Conectando la exégesis de la Carta de Derechos Fundamentales de la UE con los derechos garantizados en los apartados 1 y 3 del artículo 6 del CEDH, la Sentencia del TJUE afirma, un tanto lapidariamente, que esa interpretación de los artículos 47 y 48 de la Carta coincide con el alcance dado por el TEDH a los derechos homólogos reconocidos en el Convenio (invocando genéricamente al efecto los asuntos Medenica c. Suiza, Sedjovic c. Italia y Haralampiev c. Bulgaria, pero sin reproducir o glosar los razonamientos concretos del Tribunal de Estrasburgo). Y retorna seguidamente la Sentencia Melloni del TJUE al Derecho de la Unión, para hacer notar que la armonización de las condiciones de ejecución de las Euroórdenes en casos de condenas dictadas en ausencia del imputado tiende a reforzar los derechos procesales de éste (afirmación categórica que no matiza cómo esto es así en una disciplina que rebaja los derechos que estas personas tenían con la regulación anterior), a la vez que mejora el reconocimiento mutuo de las resoluciones judiciales entre Estados miembros (circunstancia, ésta sí, que resulta evidente: si se limitan los supuestos de denegación o condicionamiento de Euroórdenes, se facilita la ejecución, y por tanto se reconocen en mayor medida, de las resoluciones judiciales de los Estados miembros emisores de aquéllas).

Finalmente, en cuanto a la tercera y última cuestión prejudicial, la respuesta del TJUE, un tanto parca a la vez que categórica en términos de primacía del Derecho de la Unión ${ }^{17}$, consistió esencialmente en rechazar la exégesis propuesta

17 Como ha destacado I. Torres Muro, «La condena en ausencia: unas preguntas osadas (ATC 86/2001, de 9 de junio) y una respuesta contundente (Sentencia del Tribunal de Justicia de la Unión Europea 
por el TC español. Afirma, en concreto, la Sentencia prejudicial sobre el Asunto Melloni que un Estado no puede, en contra de lo previsto en el artículo 4 bis, apartado 1, de la Decisión marco 2002/584, condicionar la ejecución de una Euroorden transmitida para el cumplimiento de una condena penal dictada en rebeldía a requisitos cuyo objeto sea evitar una interpretación limitadora de los derechos fundamentales reconocidos por su Constitución nacional o lesiva de éstos. Según el TJUE una compresión tal del artículo 53 de la Carta menoscabaría el principio de primacía del Derecho de la Unión, característica esencial del ordenamiento de ésta, incluso frente a disposiciones nacionales de rango constitucional, invocando en apoyo de dicha afirmación algunos de sus grandes leading cases en materia de primacía (como la Sentencia Internationale Handelsgesellschaft). Y, repárese en el detalle, sin sustentar esta afirmación en disposición alguna de Derecho originario de la UE.

Es más, la Sentencia Melloni del TJUE expresamente condiciona la aplicación del artículo 53 de la Carta a que no se afecte al nivel de protección previsto por ésta. Pero la Sentencia, en su lectura de dicho precepto, desliza dos condiciones adicionales (y restrictivas de la aplicabilidad del superior estándar nacional de protección) que no aparecen en la literalidad de la norma: el estándar nacional superior es de observancia, conforme a la Sentencia Melloni, siempre que no afecte al previsto por la Carta según la interpretación que de ella realice el Tribunal, ni tampoco a la primacía, unidad y efectividad del Derecho de la Unión. Dos condiciones, estas últimas, que el artículo 53 de la Carta no establece, sino que resultan de una operación hermenéutica del TJUE que invierte la literalidad del precepto, pues si éste prescribe que ninguna disposición de la propia Carta puede entenderse como limitativa o lesiva de los derechos humanos y libertades fundamentales reconocidos, en particular, por las Constituciones de los Estados miembros, la Sentencia Melloni del TJUE añade, en exégesis de ese mismo artículo, que sí tengan tal eficacia limitativa la primacía, unidad y efectividad del Derecho de la Unión.

\section{LA RECEPCIÓN DE LA SENTENCIA PREJUDICIAL EN LA STC 26/2014: UNA REMISIÓN (NO TAN SUPERFLUA) A LA DTC 1/2004 Y UN (PREVISIBLE) GIRO JURISPRUDENCIAL RESPECTO A LAS GARANTÍAS CONSTITUCIONALES DE LAS EUROÓRDENES PARA SUPUESTOS DE CONDENA IN ABSENTIA}

Prácticamente al año de la respuesta prejudicial del TJUE recayó la STC 26/2014, de 13 de febrero, con la que concluye el diálogo entre ambos Tribunales, al menos en el Asunto Melloni. Frente al tono amigable y la estrategia

de 26 de febrero de 2013)», cit., passim. 
persuasoria que latía en el ATC 86/2011, esta Sentencia constitucional parece acusar el tono adusto perceptible en la resolución prejudicial del TJUE. Y es que si ésta reafirma el principio de primacía, individualizándolo en la Decisión marco reguladora de la Euroorden, la STC 26/2014 hace lo propio con los contralímites constitucionales a la integración europea, con expresa evocación de lo señalado en su día al respecto en la DTC 1/2004.

Ello sólo puede entenderse como reacción del Pleno del TC, para reafirmar su posición de Tribunal de last resort y cumbre jurisdiccional del sistema normativo estatal español, con la Constitución a la cabeza. De hecho, la remisión a la DTC 1/2004 y su doctrina de los contralímites es prácticamente «una incrustación» en el hilo discursivo, al no guardar directa relación con la resolución del amparo. Precediendo los fundamentos jurídicos dedicados a relatar las vicisitudes procesales del caso, el primero de los que pueden considerarse sustanciales tiene por único objeto insertar en el discurso del TC este recordatorio de la DTC 1/2004, hilvanado con la sola mención de que con él se completa la Sentencia prejudicial del TJUE en el Asunto Melloni.

$\mathrm{Y}$ es que nada tiene que ver esta doctrina, en realidad, con la resolución que la STC 26/2014 da al correspondiente recurso de amparo, al menos en el sentido desestimatorio que finalmente cobra el fallo. De hecho, acepta el TC a lo largo de los siguientes fundamentos el criterio del TJUE sobre la interpretación y validez de la Decisión marco reguladora de la Euroorden, y especialmente en torno a la prohibición de condicionar su concesión a la disponibilidad de juicio rescisorio en el Estado emisor para la ejecución de condenas penales graves pronunciadas en ausencia voluntaria del acusado objeto de entrega. De igual modo, la STC 26/2014 admite el sentido interpretativo de la jurisprudencia del TEDH que, brevemente pero con bastante claridad, expone la STJUE sobre el Asunto Melloni.

Así, y reiterando doctrina del TEDH en torno a que el derecho a nuevo juicio presencial de las personas condenadas en rebeldía se condiciona a que no hayan renunciado de manera inequívoca a su derecho a comparecer en juicio, habiendo sido debidamente informadas en las diligencias, aparece a continuación en la Sentencia 26/2014 el matiz que supone el giro del TC con respecto a su jurisprudencia antecedente, cuando indica que el TEDH ha reconocido que no se infringe el artículo 6 del CEDH cuando el acusado, debidamente emplazado, decida libremente renunciar a su presencia en el juicio, y cuente durante éste con la asistencia de Abogado para la defensa de sus intereses.

A esta invocación de la jurisprudencia del TEDH se une la aceptación en la STC 26/2014, asimismo explícita, de la doctrina establecida en la Sentencia prejudicial del TJUE sobre el Asunto Melloni, como elemento adicional de interpretación del artículo 24.2 de la Constitución por la vía del artículo 10.2 de ésta, para arribar a la conclusión de que no se produce vulneración de dichos derechos, aunque no se condicione la concesión de Euroórdenes a la disponibilidad de juicio rescisorio en el Estado miembro emisor con presencia del afectado, cuando 
voluntariamente haya dejado éste de comparecer en el juicio penal, pero haya designado Abogado que le represente y defienda en él ${ }^{18}$.

Nada dice expresamente, por el contrario, la STC 26/2014 sobre la incidencia del artículo 53 de la Carta en la decisión que en ella se da al amparo, por lo que, al menos implícitamente, parece también que el TC ha aceptado en este punto lo resuelto por la Sentencia prejudicial del TJUE. De hecho, el viraje en cuanto al sentido del canon internacional interpretativo del artículo 24.2 de la Constitución española, tanto a la luz de la jurisprudencia del TEDH, cuanto a la del TJUE (Sentencia prejudicial en el Asunto Melloni incluida), ha permitido eliminar la colisión entre el referido precepto y la Decisión Marco reguladora de la Euroorden. Y al desaparecer la antinomia, lo hace también la necesidad de aplicar el artículo 53 de la Carta para resolverla.

Pero tal vez quepa ver una referencia implícita de la STC 26/2014 a dicho artículo, el 53 de la Carta, y a la interpretación que le da la Sentencia prejudicial del TJUE en el Asunto Melloni. Quizás sea ésa la razón de que el primer fundamento sustancial de la mencionada Sentencia del TC invoque la doctrina de los derechos fundamentales constitucionalmente reconocidos como contralímites materiales a la integración europea, que expuso la DTC 1/2004, pues se consideraba en ésta condición de constitucionalidad del precepto equivalente en el Proyecto de Constitución europea, precisamente, el valor que dicho precepto tenía de estándar mínimo europeo compatible con un eventual estándar nacional superior, según parecía desprenderse de la formulación literal del mismo.

Estaría advirtiendo la STC 26/2014, con esta evocación de la DTC 1/2004, que la constitucionalidad interna de la Carta como texto internacional de Derecho originario de la UE (valor que le otorga el artículo 6.1 del TUE) dependería de que el artículo 53 de aquélla efectivamente tenga ese valor de estándar mínimo europeo de protección de los derechos compatible con un nivel nacional superior. Nótese, en contraste, que el ATC 86/2011, de planteamiento del triple reenvío prejudicial, no menciona a la DTC $1 / 2004$ en lo relativo a los derechos constitucionalmente protegidos como contralímite interno a la integración supranacional, ni la interpretación que en ella otorgaba al antes referido entendimiento del artículo 53 de la Carta como cláusula de estándar mínimo, y su

18 J. I. Ugartemendía Eceizabarrena y S. Ripol Carulla, «Del recato de la jurisprudencia del Tribunal Constitucional...», cit., apdos. III, IV.1 y IV.2, ponen de relieve, tanto el hecho de esta aceptación en el caso concreto del Asunto Melloni, como los inconvenientes estructurales que de ella pueden derivarse, por haberse empleado en la STC 26/2014 el artículo 10.2 de la Constitución como vía de entrada interpretativa del canon jurisprudencial del TJUE, en lugar de optar por la del artículo 93 de la misma, puesto en relación con los artículos 6 del TUE y 53 de la Carta, a consecuencia del carácter difuso del control del cumplimiento del Derecho de la UE (incluida la Carta y los derechos en ella reconocidos) merced a la cuestión prejudicial que cualquier órgano jurisdiccional ordinario puede interponer. Asimismo se exploran en el referido artículo doctrinal (apdo. IV.3) alternativas (entre ellas, residenciar en el TC vía reforma de la LOTC el control de «comunitariedad» de la ley) que, pese a su indudable interés, exceden del objeto y extensión del presente trabajo. 
papel, en tal condición, como requisito de validez constitucional interna, pero el Pleno del TC pareció adoptar en dicho Auto una estrategia «amigable» de persuasión hacia el TJUE, aunque a la postre no dio resultado.

Que no se hable de forma específica en la STC 26/2004 del artículo 53 de la Carta, puede deberse a que la diferencia de niveles de protección de los derechos entre la Decisión marco del tercer pilar de la Unión y el ordenamiento interno español surgió a partir de una línea jurisprudencial interpretativa del propio TC respecto a un precepto constitucional que nada decía específicamente al respecto, y en mitad de una tesitura en que evadieron la justicia penal de otros Estados miembros de la UE personas sentenciadas en ellos por delitos muy graves. No obstante, la remisión de la STC 26/2014 a la DTC 1/2004, y su doctrina de los derechos constitucionalmente reconocidos como contralímites materiales a la integración, tal vez puedan fundamentar en el futuro la activación de un control interno del respeto a esos contralímites cuando, por ejemplo, esté en juego la primacía de una norma europea que otorgue un nivel de protección inferior a un derecho constitucionalmente reconocido de manera que colisione, no ya con una interpretación jurisprudencial discutible y reversible del TC, como ha sucedido en el Asunto Melloni, sino con la propia literalidad del correspondiente precepto reconocedor del mismo derecho en la Constitución española. O quizás más específicamente, en caso de colisión con el contenido esencial del mismo, barrera que el artículo 53.1 de la propia Constitución impone a todo desarrollo legislativo de los derechos.

Se ha dicho que el ATC 86/2011 ha permitido al TC rectificar preguntando ${ }^{19}$. Pero las respuestas ni siquiera han sido «interesantes», sino, a lo más, oportunistas. El TJUE ha aprovechado la ocasión, que le brindaba el TC español, para reafirmar la primacía del Derecho de la Unión sobre las Constituciones nacionales en un aspecto tan sensible como el superior nivel de protección de los derechos que éstas puedan ofrecer con respecto al dispensado por el Derecho de la UE. Incurriendo sin titubeos en el riesgo que apuntaba el propio ATC 86/2011, la STJUE sobre el Asunto Melloni priva de contenido propio al artículo 53 de la Carta, y lo convierte en eco repetitivo del artículo 51, obviando la dicción textual del precepto. En otras palabras, el TC ha dado al TJUE la oportunidad, no ya de preservar la clásica jurisprudencia de este último sobre la primacía del Derecho comunitario, sino además de "primar la primacía» sobre la redacción, nada menos, que de un precepto de Derecho originario (en virtud del artículo 6.1 del TUE): el artículo 53 de la Carta de los Derechos Fundamentales.

Se ha afirmado también en la doctrina española que el ATC 86/2011 formulaba unas preguntas osadas (Ignacio Torres $\mathrm{MURO}^{20}$ ). Pero, más que osadas, el

19 M. Revenga SÁnCHeZ, «Rectificar preguntando. El Tribunal Constitucional acude al Tribunal de Justicia...", cit.

20 I. Torres Muro, «La condena en ausencia: unas preguntas osadas (ATC 86/2011) y una respuesta contundente (Sentencia del Tribunal de Justicia de la Unión Europea de 26 de febrero de 2013», cit. 
contenido y el discurso de la STC 26/2014, subsiguiente a la Sentencia prejudicial del TJUE sobre el Asunto Melloni, confirman que esas preguntas tal vez fueran superfluas. Esto es, que parafraseando de nuevo a Miguel Revenga Sánchez ${ }^{21}$, no era necesario preguntar para rectificar. Máxime, cuando a consecuencia de las preguntas se ha obtenido el mencionado e inesperado efecto general, trascendiendo de las cuestiones concretas que se ventilaban en el propio Asunto Melloni: la imposibilidad de hacer prevalecer el estándar eventualmente superior de protección de los derechos resultante de la Constitución nacional sobre el propio del Derecho de la Unión cuando se trate de la aplicación de este último por las autoridades del correspondiente Estado miembro. Doctrinalmente se ha llegado a plantear entre nosotros, con respuesta negativa hasta ahora ${ }^{22}$, si ello pondría en tela de juicio la identidad constitucional de España como Estado, en los términos del artículo 4.2 del TUE. Es de notar que el Gobierno español no invocó en el procedimiento prejudicial ante el TJUE durante el Asunto Melloni la cláusula de identidad constitucional ${ }^{23}$, y también que concurrió con su voto afirmativo a la aprobación en 2009 de la reforma de la Decisión Marco que introdujo la prohibición de la condicionalidad en casos de condenas en ausencia, al mismo tiempo que el TC reafirmaba dicha condicionalidad como requisito de constitucionalidad interna de las resoluciones judiciales concediendo la ejecución de Euroórdenes para el mismo tipo de supuestos ${ }^{24}$.

Y, dicho sea de paso, no sólo se ha obtenido el referido efecto inesperado con el triple reenvío prejudicial, sino además una extensión o ampliación del tradicional principio de primacía, que si antes de la Sentencia Melloni del TJUE quedaba confinado al ya de por sí amplio ordenamiento jurídico comunitario, dicha Sentencia prejudicial lo ha extendido al Derecho del tercer pilar, en una suerte de «supercasación» comunitaria de la anterior Sentencia Pupino del propio TJUE (que no atribuía primacía a este Derecho de la Unión de origen intergubernamental, sino sólo una eficacia «moldeadora» de la interpretación del Derecho nacional, con el relevante límite del respeto a la literalidad de las disposiciones internas aplicables) ${ }^{25}$. Un Derecho que es de origen intergubernamental, y no

21 M. REvenga SánCHez, op. cit.

22 Acerca de esta cuestión, para descartar la afectación concreta en la Sentencia Melloni, véanse las interesantes consideraciones de J. I. Ugartemendía Ezeizabarrena y S. Ripol CARUlla, «La Euroorden ante la tutela de los derechos fundamentales. A propósito de la STJ Melloni, de 26 de febrero de 2013, C-399/11», Civitas. Revista Española de Derecho Europeo, 46, 2013, especialmente pp. 180 y ss.

23 Como puso de relieve el Abogado General Sr. Yves Bot en sus Conclusiones sobre el Asunto Melloni (punto 141), identificando la posición del Reino de España con la expresada por el Gobierno español durante la tramitación de la cuestión prejudicial: Vid., al respecto, P. MARTín RoDRíGUEZ, «Crónica de una muerte anunciada: Comentario a la Sentencia del Tribunal de Justicia (Gran Sala), de 26 de febrero de 2013, Stefano Melloni, C-399/11, Revista General de Derecho Europeo, n. ${ }^{\circ} 30,2013$, p. 14.

24 De nuevo, P. MarTín Rodríguez, op. cit., pp. 11 y 12.

25 Sentencia del Tribunal de Justicia (Gran Sala), de 16 de junio de 2005, María Pupino, C-105/03. Sobre el sentido y contenido de esta Sentencia, entre un amplio tratamiento doctrinal, pueden mencionarse aquí los trabajos de D. SARmiEnto, «Un paso más en la constitucionalización del tercer pilar de la Unión 
supranacional. Y, sobre todo, un Derecho, el del tercer pilar, desprovisto de efecto directo por previsión del Derecho originario (antiguo tenor del artículo 34.2 del TUE, mantenido en vigor a estos efectos por el artículo 10 del Protocolo n. 36 sobre las disposiciones transitorias, anejo a los Tratados de la Unión y de Funcionamiento de la Unión, e introducido por el Tratado de Lisboa).

La STC 26/2014 parece cerrar el diálogo con el TJUE, y de hecho lo hace con respecto al Asunto Melloni. Pero ese diálogo puede reabrirse en cualquier momento, cuando, como antes se decía, surja la antinomia, más que con una línea jurisprudencial del TC, con la literalidad de preceptos situados en la cúspide del ordenamiento: esto es, con preceptos de la Constitución española en materia de derechos fundamentales, especialmente los susceptibles de amparo constitucional, procedimiento que, como atestigua el caso aquí analizado, puede abrir nuevamente una vía de interlocución entre ambos Tribunales.

$$
* * *
$$

TITLE: Supremacy of the Constitution versus primacy of EU Law on fundamental rights: Concordances and discordances between the Constitutional Court and the EU Court in the Melloni case

AвSTRACT: This paper surveys the first direct judicial dialogue between the Spanish Constitutional Court and the Court of Justice of the European Union on the European Arrest Warrant and the interpretation of Article 53 of the Charter of Fundamental Rights of the EU when the national level of protection of rights is higher than that provided by a rule of secondary legislation of the Union. It highlights the possible tensions between constitutional supremacy and primacy of European Union law, and the evocation made by the Constitutional Court of its doctrine on rights constitutionally recognized as limits to the European integration contained in the judgment which closes the dialogue between both Courts within the so-called Melloni case.

RESUMEN: Se analiza en este artículo el primer diálogo judicial directo entre el TC español y el Tribunal de Justicia de la UE, sobre la Euroorden y la interpretación del artículo 53 de la Carta de los Derechos Fundamentales de la UE cuando el nivel nacional de protección de los derechos es superior al dispensado por una norma de Derecho derivado de la Unión. Se ponen de manifiesto las posibles tensiones entre supremacía constitucional y primacía del Derecho de la Unión Europea, y la evocación por el Tribunal Constitucional de su doctrina de los derechos constitucionalmente reconocidos como límites a la integración en la Sentencia que cierra el diálogo con el Tribunal de Justicia en el Asunto Melloni.

KEY wORDS: Constitutional supremacy, EU Law primacy, judicial dialogue.

Palabras Clave: Supremacía constitucional, primacía del Derecho de la UE, diálogo judicial.

FECHA DE RECEPCIÓN: 09.03.2016

FECHA DE ACEPTACIÓN: 01.02.2017

\footnotetext{
Europea. La sentencia Maria Pupino y el efecto directo de las decisiones marco», Revista electrónica de estudios internacionales (REEI), n. ${ }^{\circ}$ 10, 2005, M. FLETCHER, «Extending «indirect effect» to the third pillar: The significance of Pupino", European law review, n. ${ }^{\circ}$ 6, 2005, pp. 862-878, o V. BAzzocchi, «Il caso Pupino e il principio di interpretazione conforme delle decisioni-quadro», Quaderni costituzionali, n. ${ }^{\circ}$ 6, 2005, pp. $884-886$.
} 